\title{
Electrochemical Detection of Iron in a Lixiviant Solution of Polluted Soil Using a Modified Glassy Carbon Electrode
}

\author{
D. I. Anguiano, ${ }^{1}$ M. G. García, ${ }^{1,2}$ C. Ruíz, ${ }^{1}$ J. Torres, ${ }^{1}$ I. Alonso-Lemus, ${ }^{3}$ \\ L. Alvarez-Contreras, ${ }^{3}$ Y. Verde-Gómez, ${ }^{4}$ and E. Bustos ${ }^{1}$ \\ ${ }^{1}$ Centro de Investigación y Desarrollo Tecnológico en Electroquímica S.C., P.O. Box 064, 76700 Pedro Escobedo, QRO, Mexico \\ ${ }^{2}$ Universidad de Guanajuato, Lascuraín de Retana, 36000 Guanajuato, GTO, Mexico \\ ${ }^{3}$ Centro de Investigación en Materiales Avanzados, S.C., Miguel de Cervantes 120, Complejo Industrial Chihuahua, \\ 31109 Chihuahua, CHIH, Mexico \\ ${ }^{4}$ Instituto Tecnológico de Cancún, Avenida Kabah Km. 3, 77500 Cancún, QROO, Mexico
}

Correspondence should be addressed to E. Bustos, ebustos@cideteq.mx

Received 8 May 2011; Revised 5 October 2011; Accepted 10 October 2011

Academic Editor: Adalgisa Rodrigues de Andrade

Copyright (C) 2012 D. I. Anguiano et al. This is an open access article distributed under the Creative Commons Attribution License, which permits unrestricted use, distribution, and reproduction in any medium, provided the original work is properly cited.

This paper presents preliminary results on the modification of glassy carbon electrodes with Multiwall Carbon Nanotubes with or without Polyaniline and Pt nanoparticles as electrocatalytic materials for metallic pollutants detection. Electrodes were constructed and incorporated as amperometric detectors of ionic iron electroreduction using the Flow Injection Amperometric technique in aqueous solution. The results not only revealed the modified electrode with nanotubes, polyaniline and platinum nanoparticles were the most selective and sensitive, but also provided an electroanalytic tool to analyze iron in lixiviated samples of polluted soil. The proposed iron sensor exhibited a linear response between 0 and $10 \mathrm{mM}$ with detection and quantification limits of 0.003 and $0.012 \mu \mathrm{M}$, respectively. The aqueous samples were taken from a lixiviated solution of polluted soil from Mineral de Pozos, Guanajuato, Mexico, to define the erosion grade of soil.

\section{Introduction}

The main polyvalent cations responsible for the binding of humic and fulvic acids to soil clays are $\mathrm{Ca}^{2+}, \mathrm{Fe}^{3+}$, and $\mathrm{Al}^{3+}$, which are the main micronutrients, essential for plants at requirement levels of less than $0.10 \%$. The iron forms strong coordination complexes with humic substances where the displacement of the bound metal is difficult and it may require extraction with a strong chelating agent [1]. In this way, the detection of iron can indicate the erosion grade of soil.

The most analytical techniques to measure iron, such as UV-Vis spectroscopic, atomic adsorption, and Inductively Couple Plasma Mass Spectrometry (ICP-MS), are timeconsuming test, difficult to adapt to automatic detection and destructive techniques. On the other hand, electrochemical sensors have been shown to be the best convenient tool for iron detection. Sensors with conductive materials like carbon nanotubes, which have been doped with different nanoparticles, such as $\mathrm{Pt}$, to facilitate the electron transfer and enhance their conductivity and electrocatalytic properties [2].

Sensors based on nanostructured materials have been under development in the last decade due to their selectivity for detection and quantification of different compounds. Physical and chemical properties of Carbon Nanotubes (CNTs) make them an attractive nanostructured material for different applications in a wide range of technological fields including chemistry, medicine, materials, and engineering [3], where they can be used as electrodes for electronic devices and electrochemical sensors. CNTs represent a novel carbon material which can be found as Multiwall Carbon Nanotubes (MWCNTs) or Single Wall Carbon Nanotubes (SWCNTs).

Modified microelectrodes with CNTs show better performance than conventional carbon electrodes due to the nanomaterial properties such as CNTs channels, electronic structure, and topological defects present on the tube surface 
[4]. The constitution and morphology of CNTs provide a large surface area to support metallic catalysts where the active particles can be deposited on the external walls or encapsulated inside the CNTs. Pt, Ru, Pd, and other metallic nanoparticles have been deposited on CNTs [5-7] with surface oxidized functional groups, which enhance the homogeneous distribution of the metals [8]. Also, MWCNTs modified with Pt nanoparticles have been used in detection of molecules with biological and environmental importance such as $\mathrm{H}_{2} \mathrm{O}_{2}[9]$.

Flow Injection Analysis (FIA) has been used routinely to provide sample handling automated control. FIA is based on the injection of small (usually a few $\mu \mathrm{L}$ ) aliquots of liquid sample into a moving nonsegmented continuous carrier stream of suitable liquid. The injected sample forms a zone, which is the pathway toward a detector. A peak-shaped response is usually obtained at the detector as the sample "plug" flows reach it [10]. In addition to the automatic control, FIA offers other advantages such as convective mass transport, matrix exchange and precision increment. The combination of FIA with electrochemical detection is attractive because of provide flexibility, and electrochemical detection and it can be used as a diagnostic power tool.

In order to bond the advantages of the FIA and voltamperometry techniques, a suitable electrode to be used under hydrodynamic conditions is necessary as an amperometric sensor in dynamics systems. This work describes the construction, characterization, and application of glassy carbon modified electrodes with MWCNTs or MWCNTs-PANI and Pt nanoparticles, to detect iron with more sensibility and suitable detection than conventional techniques. After the laboratory-controlled evaluation, the sensor was tested with a nonlaboratory sample using a lixiviated aqueous solution from polluted soil of Mineral de Pozos in Guanajuato, Mexico.

\section{Experimental Details}

The used reactants were as follows: dihydrogen tetrachloroplatinate $\left(\mathrm{H}_{2} \mathrm{PtCl}_{4}, 58.15 \% \mathrm{wt} \mathrm{Pt}\right)$ from Alfa Aesar and $\mathrm{H}_{2} \mathrm{SO}_{4}(98 \%), \mathrm{KCl}(97 \%), \mathrm{FeCl}_{3}$ (97\%), toluene (99\%), $\mathrm{HNO}_{3}$ (99\%), $\mathrm{HCl}$ (99\%), acetone (99\%), and ethanol (99\%) were obtained from J. T. Baker. Aniline (99\%), and potassium dichromate (99.5\%) was from Sigma brand. Ferrocene (99\%) and Ar (95\%) was obtained from Sigma Aldrich and Praxair, respectively. All aqueous solutions were prepared with deionized water $(\rho \geq 18 \mathrm{M} \Omega \cdot \mathrm{cm})$.

A sample of sandy loam soil was collected near the outcrop of weathered igneous acid rock (rhyolite) at the town of La Merced, Mineral de Pozos, Guanajuato $\left(21^{\circ} 12^{\prime} 17.9^{\prime \prime} \mathrm{N}\right.$ and $\left.100^{\circ} 29^{\prime} 40.1^{\prime \prime} \mathrm{W}\right)$. The sample was collected from the Ahorizon $(0-10 \mathrm{~cm})$ using stainless steel shovels, and having weather conditions of $293 \mathrm{~K}$ with $30 \mathrm{Km} / \mathrm{h}$ wind speed. This sample was transport in a portable refrigerator to conserve its properties just to be analyzed.

Carbon electrodes contain many chemical functional groups and different structures in their interfaces, which can dramatically affect the heterogeneous kinetics of redox reactions as well as the analyte adsorptions. These kinds of electrodes are highly sensitive to the type of surface treatment employed before the electrochemical measurement [11]. In this manner, glassy carbon electrodes (GCEs) were prepared before surface modification with MWCNTs; first, the electrode was sequentially polished using a polishing cloth (Buehler) with 1.0, 0.3, and $0.05 \mu \mathrm{m}$ of alumina in deionized water followed by sonication treatment for $10 \mathrm{~min}$ $[12,13]$.

In order to improve the surface chemical homogeneity and to have a favorable reactivity conditions, necessary for the covalent attachment of the GCE in a later stage, $\mathrm{CV}$ experiments were performed on polished electrodes to investigate the electrochemical reactivity of the electrode surface in an acidic aqueous solution $\left(0.5 \mathrm{M} \mathrm{H}_{2} \mathrm{SO}_{4}\right.$ at $298 \mathrm{~K}$ ). Voltammetry responses obtained at different potential windows have showed three potential limits, defining the predominant formation of hydroquinone, phthalic anhydride, and carboxylic acid species at $0.6 \mathrm{~V}, 1.6$, and $2.2 \mathrm{~V}$ versus $\mathrm{Ag} / \mathrm{AgCl} 3 \mathrm{M} \mathrm{NaCl}$, respectively $[14,15]$. From this information, an electrochemical treatment of the fresh electrode surface was applied at $1.6 \mathrm{~V}$ versus $\mathrm{Ag} / \mathrm{AgCl}$ by $15 \mathrm{~min}$ in order to promote the phthalic anhydride functionalization on GCE [13].

MWCNTs used in the present study were synthesized by spray pyrolysis method, as reported previously [5]. A solution of approximately $0.9 \mathrm{~g}$ of ferrocene and $25 \mathrm{~mL}$ of toluene was used as an organometallic precursor and carbon source, respectively. This solution was atomized into Vycor tubing attached to a tubular furnace at $1,173 \mathrm{~K}$ using argon flow. The MWCNTs grow in an aligned forest with iron impurities [5]. MWCNTs were cleaned and activated with concentrated nitric acid to eliminate amorphous carbon and residual iron from metallic precursor [16]. The cleaning was carried out in a reflux system at $413 \mathrm{~K}$ during $12 \mathrm{~h}$. MWCNTs were washed using three distillated water and dry at $373 \mathrm{~K}$ in air atmosphere. The final materials were kept in dry environment at room temperature.

MWCNTs-PANI was synthesized by a modified method reported previously [17] and described briefly as follows. $0.68 \mathrm{mM}$ of potassium dichromate was dissolved in $25 \mathrm{~mL}$ of $1 \mathrm{M} \mathrm{HCl}$ with constant stirring. Then $50 \mathrm{mg}$ of MWCNTs was added and the stirred continuously by $10 \mathrm{~min} .0 .1 \mathrm{M}$ aniline was mixed to begin the polymerization with constant stirring during $2 \mathrm{~h}$ at $450 \mathrm{rpm}$. The residual potassium dichromate was removed with distillated water and ethanol. $300 \mathrm{~mL}$ of acetone was added to remove the residual monomer. Finally, the CNTs were dried by $4 \mathrm{~h}$ at $373 \mathrm{~K}$ in air to evaporate the solvents and water.

Pt nanoparticles were electrodeposited using $1 \mathrm{mM}$ $\mathrm{H}_{2} \mathrm{PtCl}_{4}$ as metallic precursor in $0.5 \mathrm{M} \mathrm{H}_{2} \mathrm{SO}_{4}$ aqueous solution. Electrodes were placed at constant voltage of $-0.2 \mathrm{~V}$ versus $\mathrm{Ag} / \mathrm{AgCl}$ by $15 \mathrm{~min}$.

Cyclic voltammetry (CV) and amperometric experiments to synthetic and real samples were performed using a BAS Epsilon potentiostat from Bioanalytical Systems, Inc. All electrochemical experiments were carried out at $298 \mathrm{~K}$ in a $10 \mathrm{~mL}$ volume BAS cell equipped with a glassy carbon as working electrode $\left(0.28 \mathrm{~cm}^{2}\right)$, a platinum counter 
TABLE 1: Real area values obtained from capacitance current calculations of the different electrodes, and thermodynamic parameters of the electroreduction of iron over the different electrodes used, in $0.1 \mathrm{M} \mathrm{KCl}$ at $298 \mathrm{~K}$ : (A) Glassy Carbon Electrode, (B) Glassy Carbon Electrode-Multiwalled Carbon Nanotubes, (C) Glassy Carbon Electrode-Multiwalled Carbon Nanotubes-Polyanaline, (D) Glassy Carbon Electrode-Platinum nanoparticles, (E) Glassy Carbon Electrode-Multiwalled Carbon Nanotubes-Platinum nanoparticles, and (F) Glassy Carbon Electrode-Multiwalled Carbon Nanotubes-Polyanaline-Platinum nanoparticles.

\begin{tabular}{lccccccr}
\hline & Equation & $R^{2}$ & $C_{\mathrm{dl}} / \mu \mathrm{F} \mathrm{cm}{ }^{-2}$ & $A_{\text {real }} / \mathrm{cm}^{2}$ & $\Delta E_{p}$ & $\left|i_{\text {pc }} / /\right| i_{\text {pa }} \mid$ & Process \\
\hline A & $i_{\text {cap }}=8 \times 10^{-5} v+1 \times 10^{-5}$ & 0.6868 & $8 \times 10^{-5}$ & 1.33 & - & Irreversible \\
$\mathrm{B}$ & $i_{\text {cap }}=6 \times 10^{-5} v+3 \times 10^{-6}$ & 0.7380 & $6 \times 10^{-5}$ & 1.00 & 0.525 & 0.94 & Quasireversible \\
$\mathrm{C}$ & $i_{\text {cap }}=4 \times 10^{-5} v+7 \times 10^{-6}$ & 0.9713 & $4 \times 10^{-5}$ & 0.67 & 0.176 & 1 & Quasireversible \\
$\mathrm{D}$ & $i_{\text {cap }}=1 \times 10^{-4} v+2 \times 10^{-5}$ & 0.9256 & $1 \times 10^{-4}$ & 1.67 & 0.194 & 0.46 & Quasireversible \\
$\mathrm{E}$ & $i_{\text {cap }}=3 \times 10^{-4} v+9 \times 10^{-7}$ & 0.8096 & $3 \times 10^{-4}$ & 5.00 & 0.610 & 0.90 & Quasireversible \\
$\mathrm{F}$ & $i_{\text {cap }}=8 \times 10^{-6} v+1 \times 10^{-5}$ & 0.9333 & $8 \times 10^{-6}$ & 0.13 & 0.578 & 0.88 & Quasireversible \\
\hline
\end{tabular}

electrode, and an $\mathrm{Ag} / \mathrm{AgCl}(3 \mathrm{M} \mathrm{NaCl})$ as reference electrode. Before each electrochemical experiment, the electrolyte was deoxygenated by bubbling ultrapure nitrogen (PRAXAIR, grade 5.0 ) by at least $10 \mathrm{~min}$. During electrochemical experiments, $\mathrm{N}_{2}$ was gently blown over the solution surface. $\mathrm{CV}$ experiments were performed from -0.1 to $0.8 \mathrm{~V}$ versus $\mathrm{Ag} / \mathrm{AgCl}$ at $0.1 \mathrm{~V} / \mathrm{seg}$.

Hewlett-Packard Flow Injection Analysis (FIA) equipment model 1050 was used under a flow of $0.5 \mathrm{~mL} \mathrm{~min}^{-1}$ at $328 \mathrm{~K}$ and 80 psi.

Sample characterization by Inductively Coupled Plasma (ICP) probes, required sample digestion which was made using $5 \mathrm{~mL}$ of $2 \% \mathrm{HNO}_{3}$ solution and deionized water up to a final volume of $50 \mathrm{~mL}$ of solution. The ICP equipment employed is a Perkin Elmer, Optima 3300 model.

\section{Results and Discussions}

After GC electrode surface pretreatment, covalent attachment binder of MWCNT and MWCNT-PANI was accomplished in the following stage. The modification with PANI was in the same way to have phthalic anhydride superficial groups over the GC, as shown in Figure 1.

GCE-MWCNT and GCE-MWCNT-PANI were modified with $\mathrm{Pt}$ nanoparticles by means of an electrodeposition process. To compare the real electroactive area of the modified electrodes, the capacitive current of the doublelayer generated were calculated in each electrode using (1)

$$
i=\left(\frac{d q}{d t}\right)\left(\frac{d E}{d E}\right)=\left(\frac{d q}{d E}\right)\left(\frac{d E}{d t}\right)=C_{\mathrm{dl}}(v) .
$$

The data were obtained from cyclic voltammetry experiments at different scan rates $\left(v=0.020\right.$ to $\left.0.200 \mathrm{~V} \mathrm{~s}^{-1}\right)$, using a windows potential $\pm 10 \mathrm{mV}$ around the equilibrium potential (data no showed). The standard capacitance $\left(C_{\text {st }}\right)$ used to evaluate the area was $60 \mu \mathrm{F} \mathrm{cm}^{-2}$ to roughness electrode [18]. Hence, the $i_{\text {cap }}$ is calculated by (2):

$$
i_{\text {cap }}=\left(\frac{\left|i_{\text {cap }}^{\mathrm{a}}\right|+\left|i_{\text {cap }}^{\mathrm{c}}\right|}{2}\right) \text { versus scan rate }(v) \text {, }
$$

where $i_{\text {cap }}^{\mathrm{a}}$ : anodic current, A, $i_{\text {cap }}^{c}$ : cathode current, A.

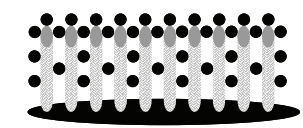

GCE-MWCNT-Pt

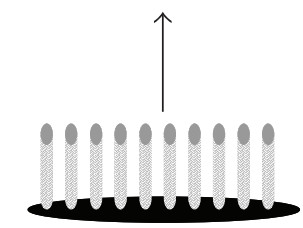

GCE-MWCNT

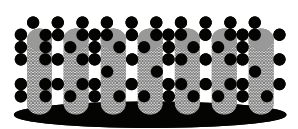

GCE-MWCNT-PANI-Pt

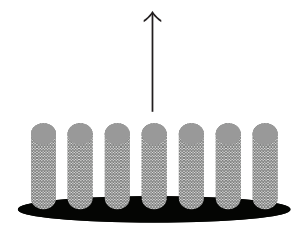

GCE-MWCNT-PANI

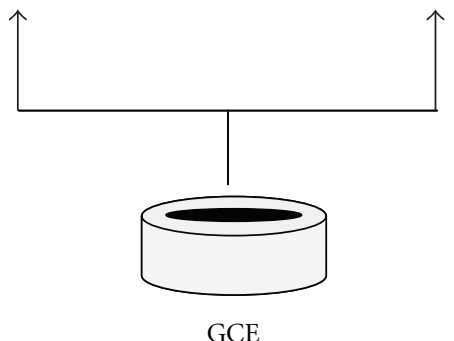

Figure 1: Schematic representation of the methodology used to prepare the modified GCE with MWCNT or MWCNT-PANI and Pt nanoparticles.

The slope of the linear relationship is the double-layer capacitance $\left(C_{\mathrm{dl}}\right)$. Then the real area was calculated as follows:

$$
A_{\text {real }}=\frac{C_{\mathrm{dl}}}{C_{\mathrm{st}}}
$$

where $C_{\mathrm{dl}}$ : double-layer capacitance, $\mathrm{F}, C_{\mathrm{st}}$ : standard capacitance, $\mathrm{F} \mathrm{cm}^{-2}, A_{\text {real }}$ : real area, $\mathrm{cm}^{2}$.

Table 1 shows the treated results from CV experiments. GCE-MWCNT-Pt showed the highest real area of $5 \mathrm{~cm}^{2}$, and GCE-MWCNT-PANI-Pt had the lowest real area $\left(0.13 \mathrm{~cm}^{2}\right)$ due to the smallest double-layer capacitance of the electrodes evaluated by the hydrophobic nature of PANI over GCE.

Once the real area was defined, the redox reaction of the $1 \mathrm{mM} \mathrm{FeCl}_{3}$ by cyclic voltammetry was obtained in $0.1 \mathrm{M} \mathrm{KCl}$ at $0.1 \mathrm{~V} \mathrm{~s}^{-1}$ under its potential window (data no showed). GCE-MWCNT-PANI-Pt electrode showed the highest electroreduction of iron $\left(\mathrm{Fe}^{3+}+\mathrm{e}^{-} \rightarrow \mathrm{Fe}^{2+}\right)$ at $0.04 \mathrm{~V}$, 
TABLE 2: Electroanalytical data for ionic iron electroreduction using different substrates considered in this study, in $0.1 \mathrm{M} \mathrm{KCl}$ at $298 \mathrm{~K}$ : Glassy Carbon Electrode (GCE), Glassy Carbon Electrode-Multiwalled Carbon Nanotubes (GCE-MWCNT), Glassy Carbon ElectrodeMultiwalled Carbon Nanotubes-Polyanaline (GCE-MWCNT-PANI), Glassy Carbon Electrode-Platinum nanoparticles (GCE-Pt), Glassy Carbon Electrode-Multiwalled Carbon Nanotubes-Platinum nanoparticles (GCE-MWCNT-Pt), and Glassy Carbon Electrode-Multiwalled Carbon Nanotubes-Polyanaline-Platinum nanoparticles (GCE-MWCNT-PANI-Pt), where $m$ : slope: sensibility, $\sigma$ : standard deviation, D. L.: detection Limit and Q. L.: quantification Limit.

\begin{tabular}{|c|c|c|c|c|c|c|}
\hline Electrode & Equation & $R^{2}$ & $m / A \mathrm{~cm}^{-2} \mathrm{M}^{-1}$ & $\sigma / 10^{-8} \mathrm{Acm}^{-2}$ & D. L. $/ \mu \mathrm{M}$ & Q. L. $/ \mu \mathrm{M}$ \\
\hline GCE & $i=0.0298\left[\mathrm{Fe}^{3+}\right]+0.00002$ & 0.9763 & 0.0298 & 1.3866 & 1.396 & 4.653 \\
\hline GCE-MWCNT & $i=0.0425\left[\mathrm{Fe}^{3+}\right]+0.000006$ & 0.9971 & 0.0425 & 0.3358 & 0.237 & 0.790 \\
\hline GCE-MWCNT-PANI & $i=0.0214\left[\mathrm{Fe}^{3+}\right]+0.00002$ & 0.9724 & 0.0214 & 0.0533 & 0.075 & 0.249 \\
\hline GCE-Pt & $i=0.0073\left[\mathrm{Fe}^{3+}\right]+0.00003$ & 0.9426 & 0.0073 & 0.2046 & 0.841 & 2.803 \\
\hline GCE-MWCNT-Pt & $i=0.0071\left[\mathrm{Fe}^{3+}\right]+0.000003$ & 0.9959 & 0.0071 & 0.0887 & 0.017 & 0.056 \\
\hline GCE-MWCNT-PANI-Pt & $i=0.1488\left[\mathrm{Fe}^{3+}\right]+0.00005$ & 0.9727 & 0.1488 & 0.0172 & 0.003 & 0.012 \\
\hline
\end{tabular}

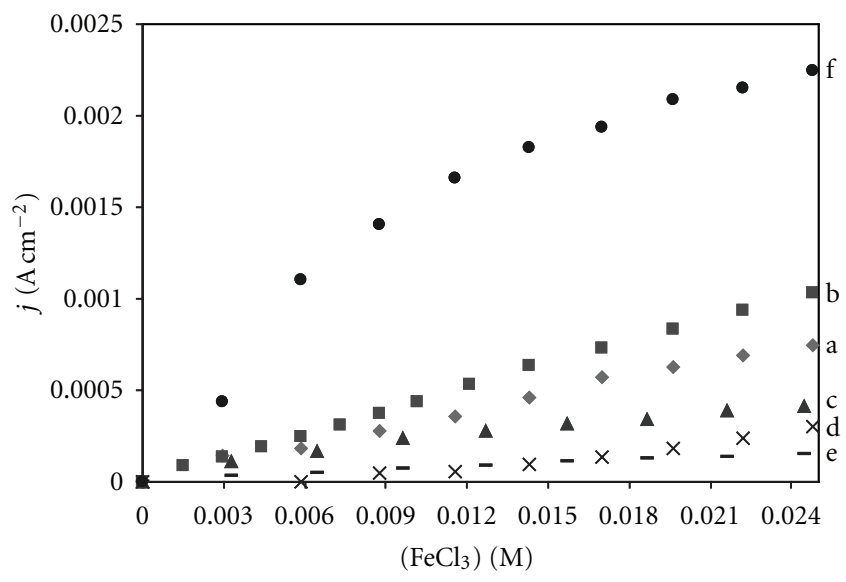

Figure 2: Calibration curves of ionic iron electroreduction over: GCE (a), GCE-MWCNT (b), GCE-MWCNT-PANI (c), GCE-Pt (d), GCE-MWCNT-Pt (e), and GCE-MWCNT-PANI-Pt (f) in $0.1 \mathrm{M}$ $\mathrm{KCl}$ at $298 \mathrm{~K}$.

although its real area was the lowest of this study, but it had the highest electrocatalytic effect by the best Pt distribution over the surface.

According to thermodynamics (Table 1), only the GCE showed an irreversible process with only one reduction peak due to the slow electronic transference. The rest of the electrodes had a quasireversible system in consequence of the material dispersion on the modified electrode which have an $i_{\mathrm{pc}} / i_{\mathrm{pa}} \cong 1$, but a $\Delta E_{p} \neq 0.060 \mathrm{~V}$ versus $\mathrm{Ag} / \mathrm{AgCl}$.

Amperometry experiment (at $\mathrm{pH}$ 7) was carried out to verify the electrochemical detection of iron using the modified electrode. The experiment was performed under constant stirring conditions at a constant applied potential corresponding to the ionic iron reduction on all substrates. Different concentrations of $\mathrm{Fe}^{3+}$ were used as shows in Figure 2. GCE-MWCNT-PANI-Pt (Figure 2(f)) showed two concentration ranges to detect $\mathrm{Fe}^{3+}$ : one at concentrations less than $12 \mathrm{mM}$ (greater response sensitivity and the highest sensibility to detect iron) and another at levels greater than $12 \mathrm{mM}$ (lower response sensitivity).

However, other surfaces did not have saturation limit in the interval of the concentration studied, due to their thin modified film and major real surface than modified electrode with MWCNT-PANI-Pt (Table 1). Hence, the calibration curves analysis was considered up to $12 \mathrm{mM}$ of $\mathrm{FeCl}_{3}$. Table 2 shows the detection and quantification limits of the iron reduction from different modified electrodes. GCE-MWCNT-PANI-Pt presented the best electrochemical performance to detect iron, with the highest sensibility $\left(0.1488 \mathrm{~A} \mathrm{~cm}^{-2} \mathrm{M}^{-1}\right)$, the lowest detection limit (D. L. = $0.003 \mu \mathrm{M}$ ), and quantification limit (Q. L. $=0.012 \mu \mathrm{M}$ ) compare with other electrodes tested.

The sensibility is the slope of the linear graph, while D. L. and Q. L. were calculated from (4), in order of the IUPAC (International Union of Pure and Applied Chemistry), where the detection limit is the lowest detected quantity, and the quantification limit is the lowest detected concentration:

$$
\begin{gathered}
\text { D. L. }=\frac{3 \sigma}{m}, \\
\text { Q. L. }=\frac{10 \sigma}{m},
\end{gathered}
$$

where $\sigma$ is the standard deviation of the data points and $m$ is the linear relationship slope $[19,20]$.

To verify the application of electrochemical sensor in real sample (RS), it was tested in lixiviated aqueous solution of polluted soil from Mineral de Pozos, Guanajuato. The sample was a representative lixiviated liquid with metallic compounds in neutral conditions. The iron concentration in real sample was verified by cyclic voltammetry to evaluate the potential peak which was used in the FIA detection with the reaction:

$$
\mathrm{Fe}^{3+}+1 \mathrm{e}^{-} \longrightarrow \mathrm{Fe}^{2+} \text { at } 0.412 \mathrm{~V} \text { versus } \frac{\mathrm{Ag}}{\mathrm{AgCl}} .
$$

$\mathrm{FeCl}_{3}$ concentration in RS was added to verify the presence of iron in the sample, and its answer increased and corroborated that current density increase with the increase of the $\mathrm{FeCl}_{3}$ concentration using the GCE-MWCNT-PANI-Pt sensor with any interference by other ions, and compounds of real sample.

Figure 3 shows the lineal performance between CV peak and iron concentration. A peak shift is observed due to 


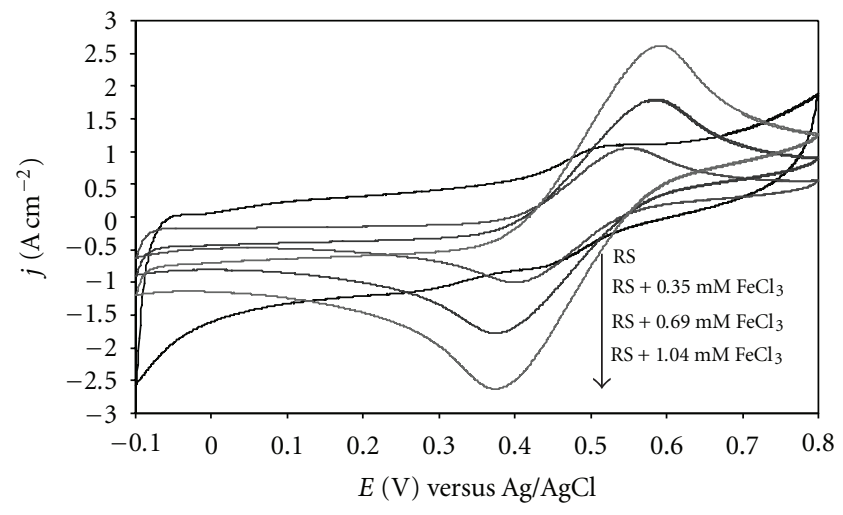

FIGURE 3: Cyclic voltammograms of real sample (RS) using GCEMWCNT-PANI-Pt with different concentrations of $\mathrm{FeCl}_{3}: 0.35$, 0.69 , and $1.04 \mathrm{mM}$, at $0.100 \mathrm{~V} \mathrm{~s}^{-1}$ in $0.1 \mathrm{M} \mathrm{KCl}$ at $298 \mathrm{~K}$.

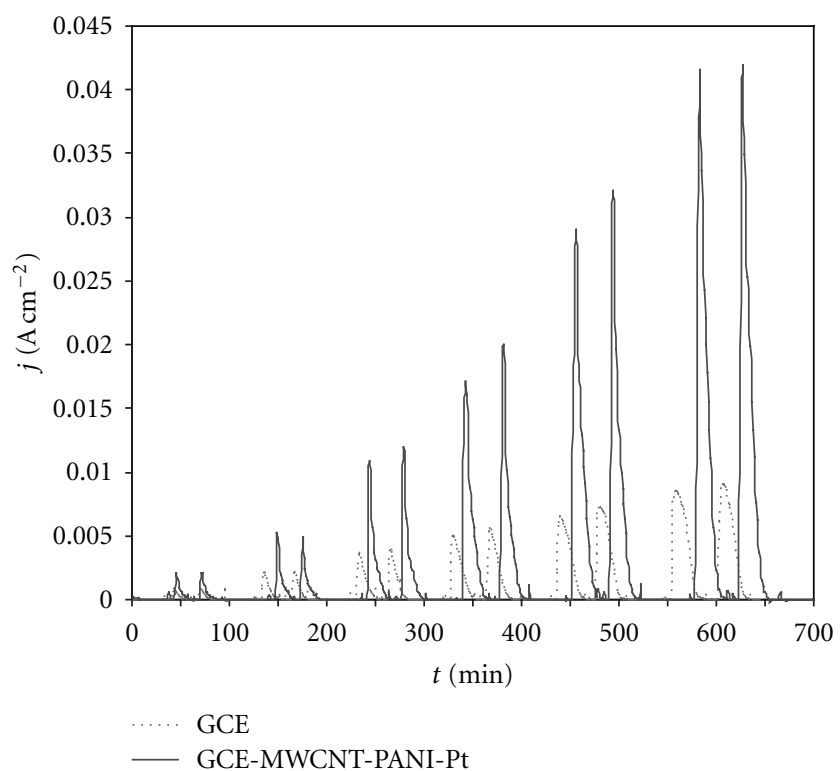

FIgURE 4: Amperometric detection with FIA technique of ionic iron at $0.412 \mathrm{~V}$ versus $\mathrm{Ag} / \mathrm{AgCl}$ over GCE and GCE-MWCNT-PANI-Pt, in $0.1 \mathrm{M} \mathrm{KCl}$ at $298 \mathrm{~K}$.

the contribution of the diffusion effect over the modified electrode as the iron concentration increases.

Amperometric detection was performed in GCE and GCE-MWCNT-PANI-Pt using FIA equipment with lixiviated aqueous solution of polluted soil. Results in Figure 4 show sharp and high signal for the modified electrode having better electroanalytical answer than the raw electrode due to the higher selectivity of the sensor. During the continuous addition of iron in presence of modified electrode, the

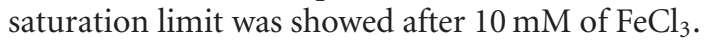

Calibration curve for iron sensor under RS was constructed using the previous data. Sensibility, detection limit and quantification limit were $0.4 \mathrm{~mA} \mathrm{~cm}^{-2} \mathrm{M}^{-1}, 46.14 \mathrm{mM}$, and $153.80 \mathrm{mM}$, respectively. GCE-MWCNT-PANI-Pt stability was verified by the continuous addition of the same concentration of iron, where the current intensity gave the same results after 10 additions, demonstrating the reproducibility of electrochemical signal. Finally, using the equation of the calibration curve with FIA technique, the current density generated by real sample was of $2.60 \pm$ $0.0007 \mu \mathrm{A} \mathrm{cm}^{-2}$, which corresponded to $6.49 \mathrm{mM}$ of ionic iron $\left(\mathrm{Fe}^{3+}\right)$. The result is similar to that obtained by ICP, which was around $5.7 \mathrm{mM}$.

\section{Conclusions}

Different modified electrodes were synthesized using MWCNT, polyaniline, and platinum. According to the results, glassy carbon modified electrodes with carbon nanotubes and Pt nanoparticles represent an interesting alternative to be used in FIA for the determination of ionic iron. The method has been satisfactory applied in the determination of ionic iron in synthetic and real samples, where the best electrocatalytic nanocomposite film was the GCE-MWCNT-PANI-Pt nanoparticles.

Also GCE-MWCNT-PANI-Pt has good selective and sensitive surface lixiviated samples of polluted soil of Mineral de Pozos, Guanajuato, Mexico, with a detection limit of $0.003 \mu \mathrm{M}$ and a quantification limit of $0.012 \mu \mathrm{M}$ using a FIA technique with synthetic sample.

\section{Acknowledgments}

The authors thank Ciencia Básica 2007, CONACyT, no. 84955 and FOMIX-Veracruz, CONACyT, no. 9631 for the financial support to develop this research. D. I. Anguiano thanks CONACyT for the financial support.

\section{References}

[1] F. J. Stevenson, Humus Chemistry: Genesis, Composition, Reactions, John Wiley \& Sons, New York, NY, USA, 2nd edition, 1994.

[2] Y. Yang and Z. G. Lin, "In situ FTIR characterization of the electrooxidation of glassy carbon electrodes," Journal of Applied Electrochemistry, vol. 25, no. 3, pp. 259-266, 1995.

[3] Y. Chen, J. Chen, H. Hu, M. A. Hamon, M. E. Itkis, and R. C. Haddon, "Solution-phase EPR studies of single-walled carbon nanotubes," Chemical Physics Letters, vol. 299, no. 6, pp. 532$535,1999$.

[4] J. X. Wang, M. X. Li, Z. J. Shi, N. Q. Li, and Z. N. Gu, "Direct Electrochemistry of Cytochrome $c$ at a Glassy Carbon Electrode Modified with Single-Wall Carbon Nanotubes," Analytical Chemistry, vol. 74, no. 9, pp. 1993-1997, 2002.

[5] Y. Verde, A. Keer, M. Miki-Yoshida, F. Paraguay-Delgado, G. Alonso-Nuñez, and M. Avalos, "Aqueous deposition of metals on multiwalled carbon nanotubes to be used as electrocatalyst for polymer exchange membrane fuel cells," Journal of Fuel Cell Science and Technology, vol. 4, no. 2, pp. 130-133, 2007.

[6] Z. Liu, J. Y. Lee, W. Chen, M. Han, and L. M. Gan, "Physical and electrochemical characterizations of microwave-assisted polyol preparation of carbon-supported PtRu nanoparticles," Langmuir, vol. 20, no. 1, pp. 181-187, 2004.

[7] Z. Sun, L. Fu, Z. Liu, B. Man, Y. Liu, and J. Du, "Synthesis of noble metal/carbon nanotube composites in supercritical 
methanol," Journal of Nanoscience and Nanotechnology, vol. 6, no. 3, pp. 691-697, 2006.

[8] Y. Xu-Xu, P. Dai-Wen, L. Zhe-Xue, L. Jian-Quan, and T. Hua, "Electrochemical behaviour of L-Dopa at single-wall carbon naotubes," Journal of Electroanalytical Chemistry, vol. 569, no. 1, pp. 47-52, 2004.

[9] C. Guzmán, G. Orozco, Y. Verde et al., "Hydrogen peroxide sensor based on modified vitreous carbon with multiwall carbon nanotubes and composites of $\mathrm{Pt}$ nanoparticlesdopamine," Electrochimica Acta, vol. 54, no. 6, pp. 1728-1732, 2009.

[10] K. Rajeshwar and J. Ibañez, Environmental Electrochemistry: Fundamentals and Applications in Pollution Abatement, Academic Press, New York, NY, USA, 1997.

[11] B. D. Bath, H. B. Martin, R. M. Wightman, and M. R. Anderson, "Dopamine adsorption at surface modified carbon-fiber electrodes," Langmuir, vol. 17, no. 22, pp. 7032-7039, 2001.

[12] G. K. Kiema, J. K. Kariuki, and M. T. McDermott, "Compositional mapping of chemically modified glassy carbon electrodes with tapping-mode scanning force microscopy," in Fundamental and Applied Aspects of Chemically Modified Surfaces, vol. 235, pp. 280-289, Royal Society of Chemistry, London, UK, 1999.

[13] E. B. Bustos, M. G. García, B. R. Díaz-Sánchez, E. Juaristi, T. W. Chapman, and L. A. Godínez, "Glassy carbon electrodes modified with composites of starburst-PAMAM dendrimers containing metal nanoparticles for amperometric detection of dopamine in urine," Talanta, vol. 72, no. 4, pp. 1586-1592, 2007.

[14] V. M. Jovanović, S. Terzić, A. V. Tripković, K. Dj. Popović, and J. D. Lović, "The effect of electrochemically treated glassy carbon on the activity of supported Pt catalyst in methanol oxidation," Electrochemistry Communications, vol. 6, no. 12, pp. 1254-1258, 2004.

[15] H. Maeda, K. Katayama, R. Matsui, Y. Yamauchi, and H. Ohmori, "Surface improvement of glassy carbon electrode anodized in triethylene glycol and its application to electrochemical HPLC analysis of protein- containing samples," Analytical Sciences, vol. 16, no. 3, pp. 293-298, 2000.

[16] S. Y. Kang, S. H. Sung, J. H. Park, and Y. C. Kim, "Hepatoprotective activity of scopoletin, a constituent of Solanum lyratum," Archives of Pharmacal Research, vol. 21, no. 6, pp. 718-722, 1998.

[17] V. Khomenko, E. Frackowiak, and F. Béguin, "Determination of the specific capacitance of conducting polymer/nanotubes composite electrodes using different cell configurations," Electrochimica Acta, vol. 50, no. 12, pp. 2499-2506, 2005.

[18] S. Trasatti and O. A. Petrii, "Real surface area measurements in electrochemistry," Pure and Applied Chemistry, vol. 63, no. 5, pp. 711-734, 1991.

[19] A. M. Bond, S. Kratsis, S. Mitchell, and J. Mocak, "Comparison of the gold reduction and stripping processes at platinum, rhodium, iridium, gold and glassy carbon microand macrodisk electrodes," Analyst, vol. 122, no. 10, pp. 11471152, 1997.

[20] E. Bustos, J. Manríquez, G. Orozco, and L. A. Godínez, "Preparation, characterization, and electrocatalytic activity of surface anchored, prussian blue containing starburst PAMAM dendrimers on gold electrodes," Langmuir, vol. 21, no. 7, pp. 3013-3021, 2005. 


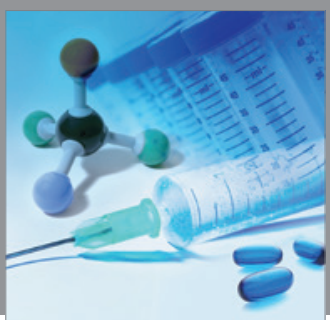

International Journal of

Medicinal Chemistry

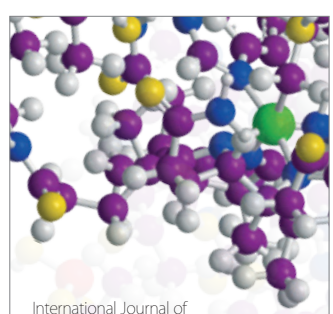

Carbohydrate Chemistry

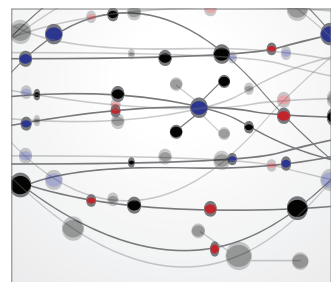

The Scientific World Journal
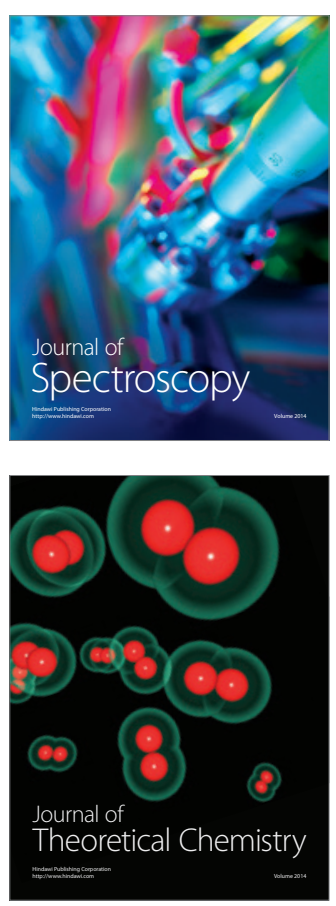
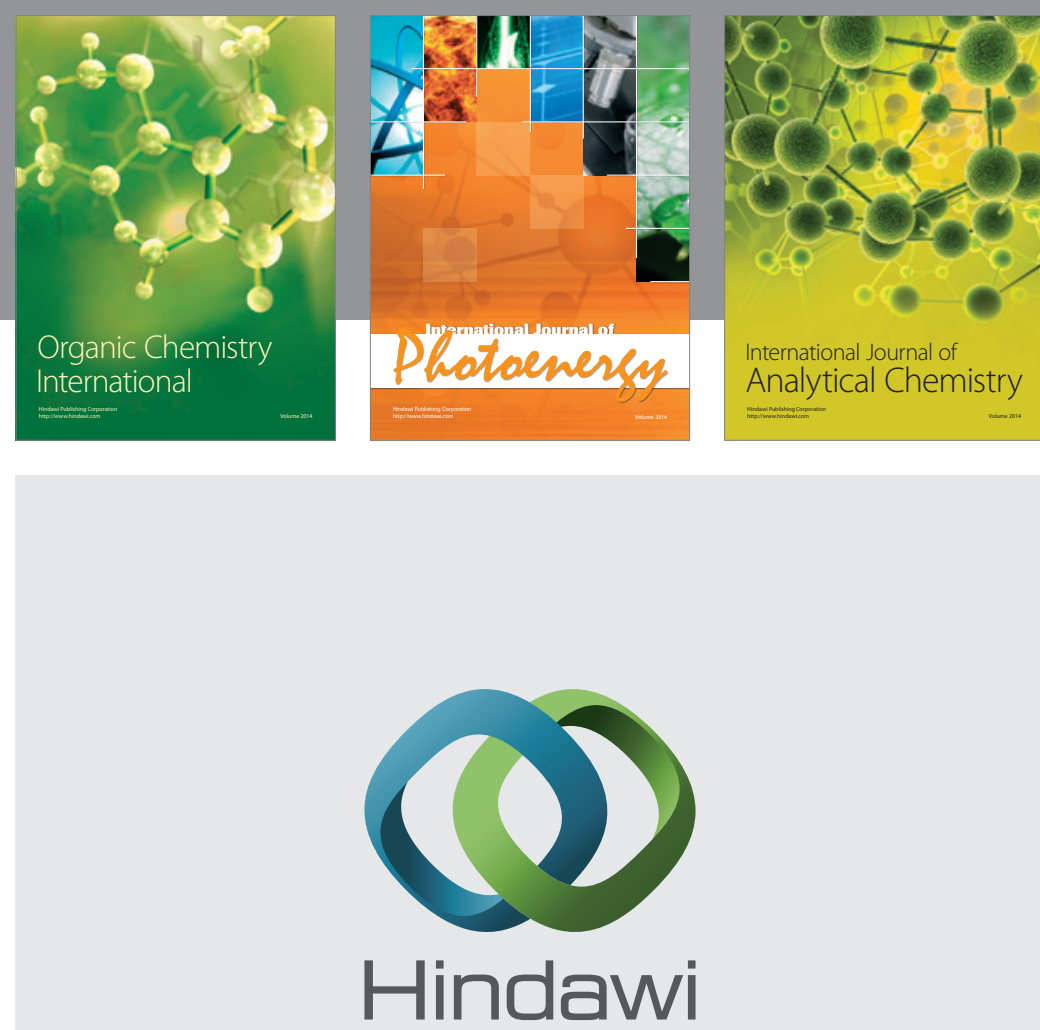

Submit your manuscripts at

http://www.hindawi.com
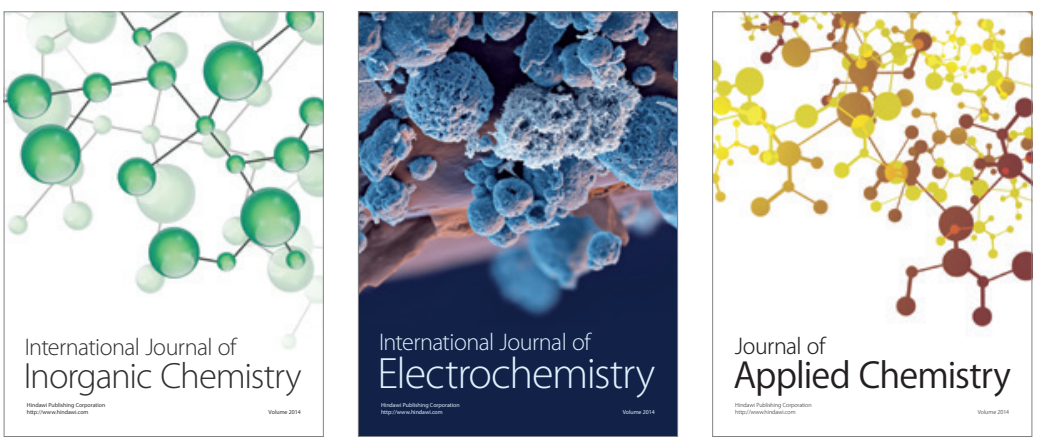

Journal of

Applied Chemistry

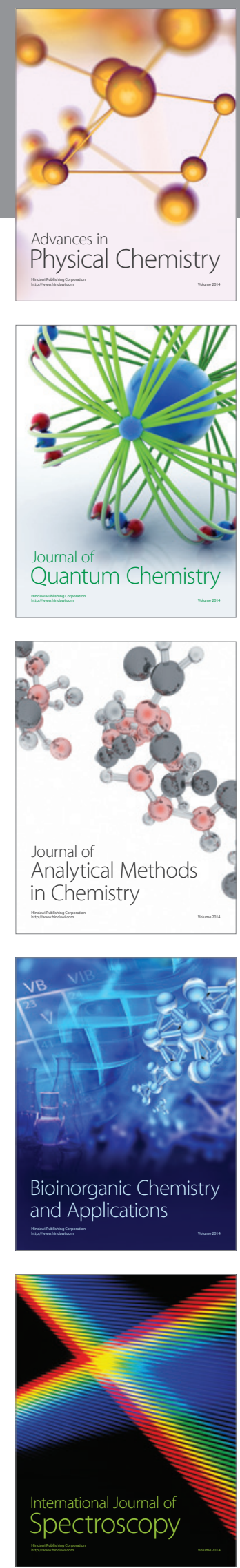